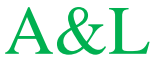

ISSN 2709-0205

Vol 1 No 2 (2020): Issue 22020

\title{
Statins in preventing stroke
}

\author{
Viktor Kuznetsov
}

State Institution “D. F. Chebotarev Institute of Gerontology NAMS of Ukraine”, Kyiv, Ukraine

Correspondence: kuznetsov66@ukr.net

Received: 21.09.2020; Accepted: 10.11.2020; Published: 12.11.2020

\begin{abstract}
Abstact. The results of a comprehensive analysis of Simvastatin (at a dose of $20 \mathrm{mg}$ per day) on the functional state of the brain in patients with atherothrombotic ischemic stroke are presented. Simvastatin provokes vasoactive action (increases linear rate of systolic blood flow velocity (LBFVsys) and decreases peripheral resistance in separate vessels of the carotid and vertebra-basilar basins), posseses antiatherogenic action (a drug decrease in the intima size, in the frequency of the atherosclerotic plagues, in the level of cholesterol, triglycerides and low density lipoproteids (LDLs). This medication leads to a positive reorganization of the bioelectric activity of the brain (increases the frequency of alpha rhythm and decreases the power of the slow rhythms), being more marked in the patients with a left-sided ischemic localization. Complex positive effects of the Simvastatin on the cerebral hemodynamic, bioelectric activity of the brain and lipid metabolism in the patients after athrothrombotic ischemic stroke allow us to recommend Simvastatin not only for the secondary prevention of stroke but also for the correction of CNS functioning in stroke patients during their rehabilitation.
\end{abstract}

Key words: ischemic stroke; statins; bioelectric activity of the brain; cerebral blood flow; atherothrombotic ischemic stroke

\author{
Abbreviations: \\ IHD - ischemic heart disease \\ LDLs - Low-density lipoproteins \\ LBFVsys - linear systolic blood flow velocity \\ HMG-CoA reductase inhibitors \\ CA - cerebral autoregulation \\ TIA- transient ischemic attack \\ $\mathrm{MI}$ - myocardial infarction \\ ADP -adenosine diphosphate \\ $\mathrm{CI}$-confidence interval \\ CRP - C-reactive protein \\ VBB - vertebra-basilar basin
}

A high level of stroke morbidity and severe disability determine the medical-social topicality of stroke problem. The last decade is marked by "stroke rejuvenation" and an increased frequency of repeated strokes. A prospective 3-year study of the patients classified as having had atherothrombotic ischemic stroke revealed a repeated ischemic stroke in $20-25 \%$. A 5-year study revealed it in $85 \%$ [1,2]. Strategy of secondary stroke prevention is formed with a consideration of pathogenetic heterogeneity of the ischemic stroke (atherothrombotic, cardioembolic, lacunar) [3]. An important link in the system of secondary 
stroke prevention after thrombotic ischemic stroke is the use of statins [1,4]. The statins have shown high effectiveness for primary and secondary ischemic stroke prevention in many multicentric investigations $[5,6,7,8,9]$.

Statins are a class of the synthetic medications (fluvastatin, atorvastatin, cevastatin and rosuvastatin) as well as the drugs derived through fungi fermentation (lovastatin, pravastatin and Simvastatin). As a result, the cholesterol concentration in the hepatocytes decreases that increases expression of the receptors to low-density lipoproteins in the liver печінці, which remove LDLs

from the circulating blood. Statins can inhibit synthesis of apopoliprotein B-100 in the liver as well as synthesis and secretion of the triglyceride-rich lipoproteins. Apart from the lipid-lowering action, the statins also possess the "non-lipid" pleiotropic properties, namely they have a protecting endothelial influence owing to an increased production of strong vasodilatory factor- nitrogen oxide; reduce systemic inflammation; possess antithrombotic immune-modulatory and antioxidant activities. A broad spectrum of statins' action necessitates a further deep study and clarification of the mechanisms of their preventive and cure influence on various functional-biochemical processes in stroke patients. [10].

Statins belong to the class of drugs often prescribed by doctors to help lower cholesterol level in the blood. By lowering its level, they help prevent heart attacks and stroke. Studies show that, in certain people, statins reduce the risk of heart attack, stroke and even death by about $25 \%$.

Based on the analysis of data characterizing the mechanisms of statins' influence on functionalbiochemical indices in patients with different variants of atherosclerosis, the statins are seen as perspective drugs for treatment of atherosclerosis and prevention of repeated injuries of cerebral and coronary blood circulation disorders.

Investigations on secondary prevention of such disorders were carried out by the Scandinavian investigators (Scandinavian - Simvastatin Survival Study -“US”) and Harvard University, showing the decrease of mortality in the patients with cardiovascular diseases receiving Simvastatin by $28-31 \%$. Secondary prophylaxis using statins reduced the frequency of cerebral blood circulation disorders [11].

The thickness of the intima-media is closely related with age and presence of arterial hypertension while its thickening represents a hypertrophic adaptive response of the smooth muscle cells to a significant hemodynamic shock [12]. Such results are explained by a positive action of statins on the plasma lipoproteids, on the endothelium function and on the structure and stability of the plaques. Apart from the described positive influence (action) on morphological and functional properties of the vascular wall, the statins normalize arterial pressure, autonomic regulation of the vessel tonus and volumic speed of the blood flow, thus eliminating hemodynamic factors of organ ischemia pathogenesis in the atherosclerotic altered basin [10,13]. The statins inhibit thrombosis and inflammation. The mechanism of antihypercoagulatory action of the statins is very complicated. The statins reduce the level of plasma fibrinogen, normalize the lipid composition of the blood membranes, inhibit the ADP-dependent aggregation of thrombocytes, inhibit the production of thromboxanes and reduce the concentration of inhibitor of the tissue activator, plasminogen-1. Based on the data characterizing the mechanisms of statins's influence on the functional-biochemical indices in patients with various forms of atherosclerosis, the statins are seen as the most perspective medication for atherosclerosis treatment and prevention of repeated disturbances of the cerebral and coronary blood circulation [14].

The results of many studies investigating the efficacy of statins as means of secondary prevention of stroke have shown that atorvastatin reduced the risk of recurrent stroke by $16 \%$ in the patients who had stroke or transient ischemic attack (TIA).

This serves the basis for using atorvastatin for prevention of repeated stroke in the patients with recurrent stroke or TIA. Prevention of stroke during treatment with statins is slowing of atherosclerosis progression in the arteries supplying blood to the brain [6].

At the same time, no less perspective is the use of statins for primary prevention of development of clinical manifestations and atherosclerosis complications in elderly patients. Study of this problem is relevant, as by the year 2020 more than $20 \%$ of population 65 plus in the industrially developed countries will make more than $20 \%$.

In the large randomized PROSPER investigation, the effects of long-term treatment with pravastatin ( $40 \mathrm{mg}$ per 24 hours) on the course and outcome of the ischemic heart disease and stroke were studied in the 70-82-year patients [4, 7]. Within a three-year treatment pravastatin slowed the production 
of plasma cholesterol in the body by 34\%, decreased the plasma level of LDLs by $34 \%$ and reduced combined risk of mortality from IHD and non-fatal MS комбінований and non-fatal myocardial infarction (MI) by 19\% (Risk Ratio 0.81 at $95 \%$ confidence interval (CI) $0.69-0.94$ ). The relative risk of stroke in active treatment group did not change significantly (Risk Ratio 1.03 at 95\% CI 0.81-1.31), whereas the relative risk of IHD and stroke mortality as well as non-fatal MI and non-fatal stroke decreased by $15 \%$ (RR 0.85 at $95 \%$ CI $0.74-0.97, \mathrm{p}=0.0014$ ). IHD mortality among those who received pravastin decreased by $24 \%$ (RR 0.76 at $95 \%$ CI $0.58-0.99, \mathrm{p}=0.043$ ). The authors reported good long-term tolerance of pravastin inclusion into combined therapy. There were no cases of myopathy, liver dysfunction and memory worsening $[13,15]$.

Clinically the most effective among statins are the Simvastatin and pravastin. In a series of large central randomized investigations (CARE, WOSCOPSUS') the authors reported the statistically significant decrease in the main clinical indices: coronary lethality by $20-42 \%$, frequency of myocardial infarction by $25-37 \%$ and frequency of stroke by $28-31 \%$.

In the Kiev Institute of Gerontology we have investigated the effects of course use of Simvastatin (20 mg daily) during two months in the elderly patients after hemispheric atherothrombotic ischemic stroke in the basin of internal carotid artery $[16,17]$.

Our investigators have analyzed the effects of course Simvastatin intake on the clinicalneurological status, cerebral hemodynamic, structure and size of atherosclerotic plaques, bioelectrical activity of the brain and lipid metabolism in patients with atherothrombotic stroke depending its hemispheric localization.

Simvastatin is a non-synthetic agent as it is the mediator of fungal fermentation. Simvastatin is metabolized through the cytochrome P450 (CYP) metabolic pathway.

The effects of course Simvastatin intake on the clinical-neurological condition, cerebral hemodynamic level, structure and sizes of atherosclerotic plaques, bioelectrical activity of the brain and lipid metabolism were analyzed in the patients with atherothrombic stroke, taking into consideration its hemispheric localization.

Simvastatin had its effect on the lipid metabolism by decreasing the concentrations of cholesterol, LDLs and triglycerides; inhibited enzymatic synthesis of endogenic cholesterol and regulated endothelium function by enhancing NO synthesis. Simvastatin depressed growth of the smooth muscle cells, depressed proliferation of the macrophages and reduced the fibrinogen contents and a high Creactive protein (CRP) level in the blood as a marker of inflammation. Owing to Simvastatin, the patients with ischemic stroke in the carotid basin had less complaints on headaches ( $78.2 \%$ before to $35.7 \%$ after), noises in the head (77.6\% before and $38.5 \%$ after) and dizziness (from $56.4 \%$ to $28.3 \%$ ). They had better walking and sleep.

Analysis of the LBFVsys dynamic in the extra- and intra-cranial vessels of the carotid basin in post-stroke patients before and after one- and two-month Simvastatin intake showed that statistically significant increase of LBFVsys in separate vessels of the carotid and VBB was registered after twomonth Simvastatin intake.

Simvastatin increased LBFVsys in separate vessels of the carotid and vertebra-basilar basins on both injured and intact sides (Fig. 1, Tab. 1). 


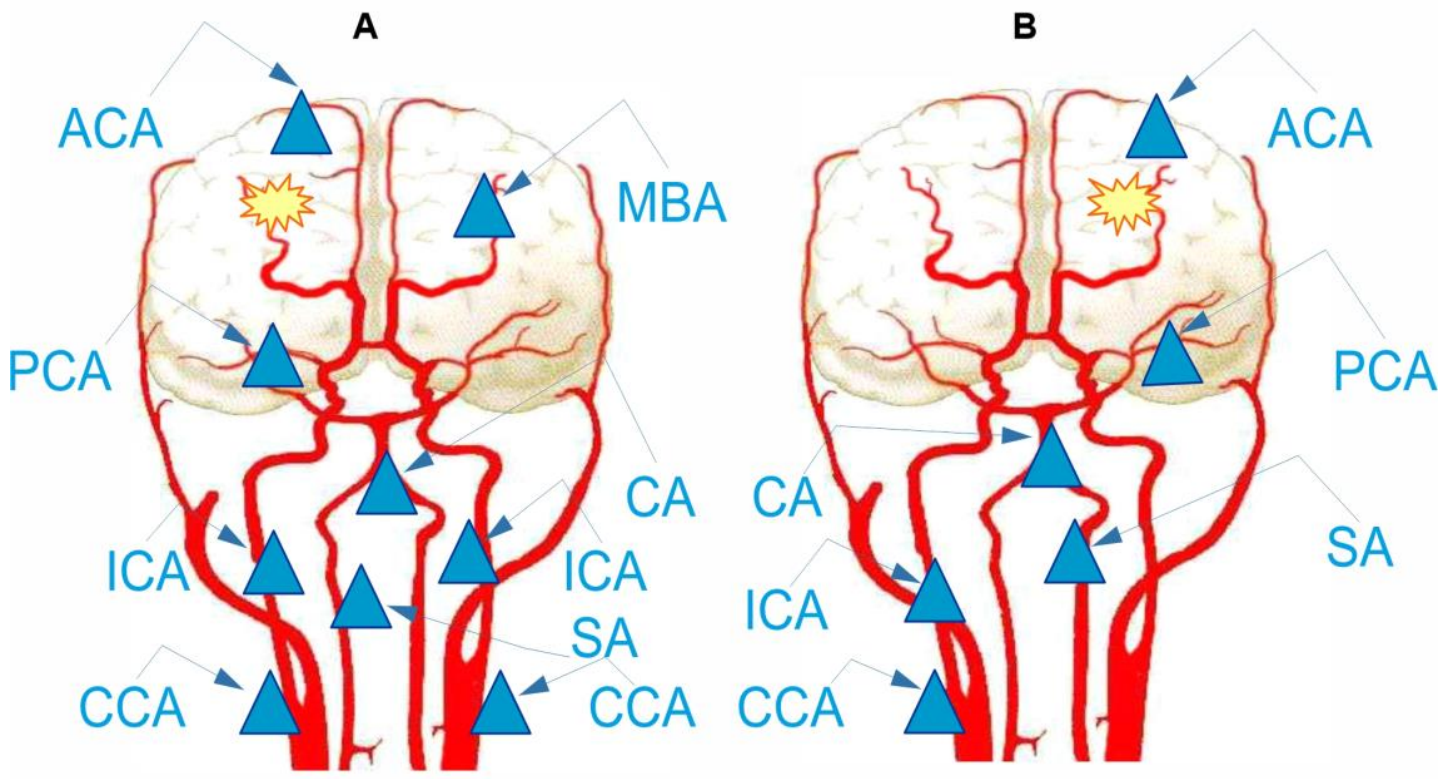

Figure1. Influence of Simvastatin on LBFVsys in the patients with ischemic stroke in the right (A) and in the left hemisphere (B)

Table 1

The dynamic of LBFVsys in the vessels of extra- and intracranial parts of the carotid and VBB in the patients with ischemic stroke under course intake of прийому Simvastatin, $\mathrm{cm} / \mathrm{s}$

\begin{tabular}{|c|c|c|c|c|c|}
\hline \multicolumn{2}{|c|}{} & \multicolumn{2}{|c|}{$\begin{array}{c}\text { Patients with right-sided stroke } \\
\text { localization }\end{array}$} & \multicolumn{2}{c|}{$\begin{array}{c}\text { Patients with left-sided stroke } \\
\text { localization }\end{array}$} \\
\cline { 3 - 6 } & $\begin{array}{c}\text { Before } \\
\text { treatment }\end{array}$ & After treatment & $\begin{array}{c}\text { Before } \\
\text { treatment }\end{array}$ & After treatment \\
\hline $\begin{array}{c}\text { Common } \\
\text { Carotid } \\
\text { Artery } \\
\text { (CCA) }\end{array}$ & Injured & $61.34 \pm 3.21$ & $71.31 \pm 2.92^{*}$ & $67.62 \pm 2.71$ & $72.85 \pm 2.84$ \\
\cline { 2 - 6 } & Intact & $69.18 \pm 3.21$ & $78.98 \pm 2.92^{*}$ & $60.19 \pm 3.16$ & $71.67 \pm 3.02^{*}$ \\
\hline $\begin{array}{c}\text { Internal } \\
\text { Carotid } \\
\text { Artery } \\
\text { (ICA) }\end{array}$ & Injured & $52.96 \pm 2.82$ & $66.40 \pm 3.17^{*}$ & $61.79 \pm 2.64$ & $65.02 \pm 2.32$ \\
\cline { 2 - 6 } & Intact & $61.9 \pm 3.2$ & $73.8 \pm 2.9^{*}$ & $50.54 \pm 2.72$ & $62.63 \pm 2.48^{*}$ \\
\hline $\begin{array}{c}\text { Anterior } \\
\text { Cerebral } \\
\text { Artery } \\
\text { (ACA) }\end{array}$ & Injured & $35.2 \pm 2.12$ & $45.62 \pm 2.29^{*}$ & $32.07 \pm 2.41$ & $36.52 \pm 2.09^{*}$ \\
\cline { 2 - 6 } & Intact & $40.58 \pm 3.20$ & $43.26 \pm 2.90$ & $36.66 \pm 2.02$ & $41.08 \pm 3.19$ \\
\hline $\begin{array}{c}\text { Midbrain } \\
\text { Artery } \\
\text { (MBA) }\end{array}$ & Injured & $83.24 \pm 3.24$ & $84.73 \pm 3.15$ & $65.83 \pm 3.32$ & $68.00 \pm 2.46$ \\
\cline { 2 - 6 } & Intact & $83.8 \pm 4.15$ & $99.46 \pm 4.18^{*}$ & $63.87 \pm 3.42$ & $65.92 \pm 3.21$ \\
\hline $\begin{array}{c}\text { Posterior } \\
\text { Cerebral }\end{array}$ & Injured & $81.71 \pm 3.56$ & $97.29 \pm 3.52^{*}$ & $66.13 \pm 2.21$ & $74.77 \pm 3.52^{*}$ \\
\hline
\end{tabular}




\begin{tabular}{|c|c|c|c|c|c|}
\hline $\begin{array}{c}\text { Artery } \\
\text { (PCA) }\end{array}$ & Intact & $104.85 \pm 2.17$ & $101.00 \pm 3.01$ & $80.77 \pm 2.71$ & $84.58 \pm 3.12$ \\
\hline $\begin{array}{c}\text { Spinal } \\
\text { Artery } \\
(\text { SA) }\end{array}$ & Injured & $43.56 \pm 2.42$ & $48.83 \pm 2.30^{*}$ & $34.47 \pm 2.35$ & $41.57 \pm 2.39^{*}$ \\
\cline { 2 - 6 } & Intact & $48.59 \pm 2.08$ & $52.05 \pm 2.20$ & $39.44 \pm 2.52$ & $44.13 \pm 2.54$ \\
\hline \multicolumn{2}{|c|}{$\begin{array}{c}\text { Circumflex Artery } \\
\text { (CA) }\end{array}$} & $48.29 \pm 2.22$ & $57.01 \pm 2.56^{*}$ & $44.03 \pm 1.87$ & $50.39 \pm 2.06^{*}$ \\
\hline
\end{tabular}

Note: ${ }^{*}-\mathrm{p}<0.05$ between indices before and after Simvastatin use

In the patients with atherosclerosis the statins slowed its progression and induced regressions, reduced thickness of the intima-media in the carotid arteries [12].

Simvastatin reduced peripheral resistance $(\mathrm{Ri}, \mathrm{Pi})$ in the injured ICAs and two spine arteries (Tab. 2). Thus, a two-month use of Simvastatin has improved hemodynamic in the extracranial vessels of the carotid vessels (PCA) and vertebrobasilar (SA) basins. In patients with right-sided stroke the increase of LBFVsys was noted in nine vessels and with left-sided stroke in six vessels.

Table 2

Dynamic of peripheral resistance ( $R i, P i)$ in extracranial vessels of the carotid and VBB in the patients after ischemic stroke with the course use of Simvastatin for one and two months

\begin{tabular}{|c|c|c|c|c|c|c|c|}
\hline \multirow{2}{*}{\multicolumn{2}{|c|}{ Vessels }} & \multicolumn{2}{|c|}{$\begin{array}{c}\text { Before } \\
\text { treatment }\end{array}$} & \multicolumn{2}{|c|}{ After one month } & \multicolumn{2}{|c|}{ Two months after treatment } \\
\hline & & $\mathbf{R i}$ & $\mathbf{P i}$ & $\mathbf{R i}$ & $\mathbf{P i}$ & $\mathbf{R i}$ & Pi \\
\hline \multirow{2}{*}{$\begin{array}{c}\text { Common } \\
\text { Carotid } \\
\text { Artery } \\
\text { (CCA) }\end{array}$} & Injured & $0.74 \pm 0.02$ & $1.78 \pm 0.08$ & $0.69 \pm 0.02$ & $1.41 \pm 0.10$ & $0.72 \pm 0.01$ & $1.63 \pm 0.09$ \\
\hline & Intact & $0.74 \pm 0.01$ & $2.17 \pm 0.11$ & $0.71 \pm 0.02$ & $1.96 \pm 0.14$ & $0.75 \pm 0.02$ & $1.94 \pm 0.13$ \\
\hline \multirow{2}{*}{$\begin{array}{c}\text { Internal } \\
\text { Carotid } \\
\text { Artery } \\
\text { (ICA) }\end{array}$} & Injured & $0.63 \pm 0.02$ & $1.14 \pm 0.12$ & $0.59 \pm 0.01$ & $1.07 \pm 0.09$ & $0.63 \pm 0.01$ & $1.06 \pm 0.11^{*}$ \\
\hline & Intact & $0.64 \pm 0.01$ & $1.17 \pm 0.13$ & $0.62 \pm 0.02$ & $1.18 \pm 0.11$ & $0.60 \pm 0.01$ & $1.17 \pm 0.09$ \\
\hline \multirow{2}{*}{$\begin{array}{c}\text { Spinal } \\
\text { Artery } \\
\text { (SA) }\end{array}$} & Injured & $0.75 \pm 0.01$ & $1.49 \pm 0.10$ & $0.68 \pm 0.01$ & $1.31 \pm 0.11$ & $0.66 \pm 0.01^{*}$ & $1.34 \pm 0.12$ \\
\hline & Intact & $0.66 \pm 0.02$ & $1.37 \pm 0.15$ & $0.65 \pm 0.02$ & $1.36 \pm 0.14$ & $0.66 \pm 0.01$ & $1.23 \pm 0.09^{*}$ \\
\hline
\end{tabular}

Note: ${ }^{*}-p<0.05$ between indices before and after Simvastatin use

Influence of simvastatin on the cerebral blood flow in the patients after atherothrombotic ischemic stroke was evaluated by the frequency of changes of the sizes and structure of the atherosclerotic plaques. The dynamic of blood biochemical indices in the blood of post-ischemic stroke patients under course simvastatin therapy was characterized by a statistically significant decrease of the cholesterol, $\beta$-lipoproteids already after one-month intake, fibrinogen and time of recalcification - after two-month simvastatin treatment (Fig. 2). 


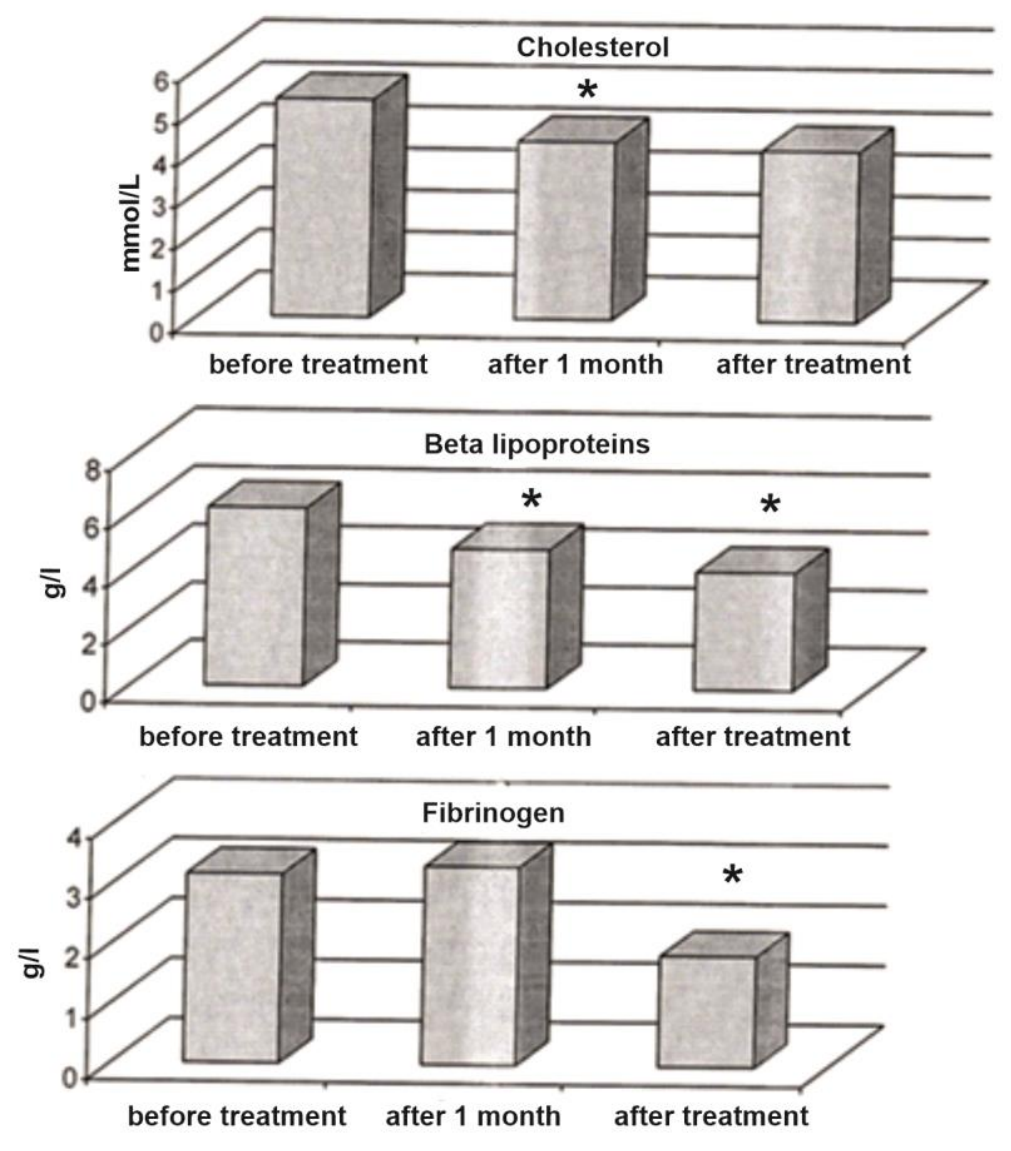

Figure 2. Dynamic of biochemical indices after course in Simvastatin treatment in post-stroke patients $\left({ }^{*}-\mathrm{p}<0.05\right.$ between indices before and after Simvastatin use)

Thus, the course simvastatin therapy in the post-stroke patients improves cerebral hemodynamic, decreases the size of atherosclerotic plaques, decreases the cholesterol, $\beta$-lipoproteindes and fibrinogen.

Intima-media thickness measurement can be formative for analysis of atherosclerotic injury [18, 19].

Tab. 3 presents the CIM characteristic in patients who developed an ischemic stroke one and two hours after simvastatin therapy. It is noteworthy that the sizes of CIM in the intact posterior connective artery reduced one month after Simvastatin discontinuation and after two months in the injured PCA. The fact that ischemic stroke decreases after course Simvastatin therapy PCA seems to be one of the mechanisms of LBFVsys increase in the PCA both in the injured and intact sides as the sizes of CIM influence the inner diameter size reflects the degree of athroclerotic injury. Decrease of CIM is the marker of improvement of morpho-functional state of PCA under simvastatin influence.

In the patients with ischemic stroke localized in the left hemisphere, the simvastatin therapy led to an active reorganization of the main EEG rhythms compared to the patients with ischemic stroke localized in the right hemisphere. In other words, with ischemic stroke localized in the left hemisphere, the power in the range of slow rhythms (delta and theta) in separate areas of the brain decreased in both hemispheres while the power in the $\alpha-1$ and $\alpha-2$ ranges and $\alpha$-rhythm frequency in both hemispheres increased [20,21]. At the same time, in the patients with stroke localization in the righthemisphere changes of the main EEG rhythms are characterized by an increased power in the range of delta-rhythm in the injured hemisphere, $\alpha-2$ rhythm power and $\alpha$-rhythm frequency in the intact hemisphere (frontal, occipital) and in the $\alpha-2$ rhythm range of both hemispheres [22]. 
Table 3

CIM dimensions in CCA after course in Simvastatin treatment in post-stroke patients, $\mathrm{mm}$

\begin{tabular}{|c|c|c|c|}
\hline Vessels & $\begin{array}{c}\text { Before } \\
\text { treatment }\end{array}$ & After one month & $\begin{array}{c}\text { Two months after } \\
\text { treatment }\end{array}$ \\
\hline Intact (CCA) & $1.10 \pm 0.03$ & $1.06 \pm 0.04^{*}$ & $0.96 \pm 0.03^{*}$ \\
\hline Injured (CCA) & $1.14 \pm 0.04$ & $1.15 \pm 0.03$ & $1.02 \pm 0.02^{*}$ \\
\hline
\end{tabular}

Note: ${ }^{*}-p<0.05$ between indices before and after Simvastatin use

Thus in the post-ischemic stroke patients, simvastatin reduced the power in the range of slow rhythms and increased the power and frequency of $\alpha$-rhythm, evidencing for harmonization of the cortical-subcortical interrelations and increases the functional activity of the brain $\alpha$-rhythm generating structures.

Thus, in the post- ischemic stroke patients the simvastatin therapy improved lipid spectrum of the blood, reduced CIM thickness and sizes of the atherosclerotic plaques, improved hemodynamic in the vessels of the carotid and vertebra-basilar basins and harmonized the structure of the brain bioelectric activity.

Thus, a two-month course simvastatin therapy (20mg daily) in the post-ischemic stroke led to an improvement of the cerebral hemodynamic (increase of LBFVsys and decrease of peripheral resistance) in separate vessels of the carotid (PCA, ICA) and VBB (SA), a decrease of the pronouncement of the atherosclerotic PCA injury: decrease of CIM and sizes of the atherosclerotic plaques, caused transformation of the hypoechogenic plaques in the hyper-echogenic), improved rheological properties of the blood by decreasing fibrinogen content and influenced on the lipid metabolism by decreasing the levels of cholesterol and $\beta$ lipoproteids.

This allows recommend to include Simvastatin not only in the system of secondary вторинної stroke prophylaxis but also for improving functional-biochemical state of the brain. In the post- ischemic stroke patients, considering the hemispheric peculiarities of the brain biodynamic action of statins bioelectrical activity of the brain can be used during rehabilitation.

Summing up the presented data about multimodal action of the statins in elderly post-ischemic stroke patients, it is important to say that:

After a two-month course simvastatin treatment (daily dose of $20 \mathrm{mg}$ ) the cerebral hemodynamic has improved, the linear blood flow velocity increased and the peripheral resistance decreased in certain vessels.

In the patients with right-hemispheric atherothrombic ischemic stroke simvastin has increased the lineal systolic blood flow speed in the PCA and ICA in the right ACA, PCA, SA and in the left MBA and decreased peripheral resistance in separate vessels of the carotid basin.

In the patients with left-hemispheric atherothrombic ischemic stroke Simvastatin has increased LBFVsys in the left ACA, PCA and SA and in the right PCA and ICA and decreased the peripheral resistance in separate vessels of the carotid and VBB basins.

After course simvastin therapy, in $60 \%$ of post- atherothrombic ischemic stroke elderly patients one observed statistically significant decrease of the intima-media complex in the PCA, size of the atherosclerotic plaques and hypoechogenic "aggressive" plaques which were transformed in the hypoechogenic and heterogenic zones. The blood levels of cholesterol, triglycerides and fibrinogen has decreased after Simavastatin therapy.

In the patients with atherothrombic ischemic stroke the Simvastatin therapy caused positive dynamic of reorganization of the brain bioelectrical activity, being more pronounced at left-sided stroke.

In the patients with left-hemispheric ischemic stroke Simvastatin has decreased the power of EEG slow rhythms (delta- and theta-rhythms) in separate areas of the brain in both hemispheres against a background of increasing power and frequency in the $\alpha$-rhythm range.

In the patients with right-hemispheric stroke, the Simvastatin effect on the bioelectrical activity of the brain was characterized by increasing power in the delta-rhythm range in the damaged hemisphere and the $\alpha 2$-rhythm in both hemispheres. 
In conclusion, the course intake of simvastatin $(20 \mathrm{mg})$ during two months by the ischemic stroke patients improves cerebral hemodynamic and lipid metabolism and harmonizes the bioelectrical activity of the brain. Therefore Simvastatin can be recommended not only for secondary stroke prophylaxis but also for its inclusion into pharmacological rehabilitation system of the patients with atherothrombic ischemic stroke.

Information about Author

Viktor Kuznetsov - DSc (Medicine), Leading Researcher of Department of Vascular Pathology of the Brain, Department of Rehabilitation of Neurological Patients; https:/orcid.org/0000-0002-2044-6507; Web of Science Researcher ID W-9357-2019 


\section{References}

1. Hippisley-Cox, J.; Coupland, C. Effect of statins on the mortality of patients with ischemic heart disease: population: cohort study with nested case-control analysis. Heart 2006, 92, 752-812. doi:10.1136/hrt.2005.061523

2. Harada, M.; Miyoshi, H.; Ootsuka, H; Taoka, Y.; Tanouchi, M; Nishitani, H. Accuracy and clinical utility of quantitative proton magnetic resonance spectroscopy (MRS) on phantom and chronic cerebral ischemia. Nippon Igaku Hoshausen Gakkai Zasshi 1996, 56, 6, 405-410.

3. Isaikin, A.I. Patogeneticheskiye aspekty terapii ishemicheskogo insulta [Pathogenetic aspects of ischemic stroke therapy]. Difficult patient (in Russian) 2010, 4, 21-25.

4. Mohr, J.P.; Choi, D.W.; Grotta, J.C.; Weir, B.; Wolf, Ph.A. Stroke: pathophysiology, diagnosis, and management. Churchill Livingstone: Philadelphia, 2004; 1616.

5. Adams, R.J.; Chimowitz, M.I.; Alpert, J.S.; Awad, I.A.; Cerqueria, M.D. et al. Coronary risk evaluation in patients with transient ischemic attack and ischemic stroke: a scientific statement for health carer professionals from the Stroke Council and the Councilon Clinical Cardiology of the American Heart Association. American Stroke Association. Stroke 2003, 34, 23102322.doi:10.1161/01.CIR.0000090444.87006.CF

6. Amarenco, P; Bogouslavssky, J.; Callahan , A.; Goldstein, L.B.; Hennerici, M. et al. Highdose atorvastatin after stroke or transient ischemic attack. N. Engl. J. Med. 2006; 355: 549-59. doi: 10.1056/NEJMoa061894

7. O'Donnell, M.; Xavier, D.; Liu, L.; Zhang, H.; Chin, S.L. et al. Risk factors for ischemic and intracerebral haemorrhagic stroke in 22 countries (the INTERSTROKE study): a case-control study. Lancet 2010, 376, 112-123. doi:10.1016/s0140-6736(10)60834-3

8. Giral, P.; Neumann, A.; Weill, A.; Coste, J. Cardiovascular effect of discontinuing statins for primary prevention at the age of 75 years: a nationwide population-based cohort study in France. European Heart Journal 2019; 40, 43: 3516-3525. Doi:10.1093/eurheartj/ehz458

9. Influence of pravastatin and plasma lipids on clinical events in the West of Scotland Coronary Prevention Study (WOSCOPS). Circulation 1998, 97, 15, 1440-1445. doi:10.1161/01.CIR.97.15.1440

10. Kumbhani, D.J. Treat Stroke to Target. The American College of Cardiology 2020, 45-50.

11. Jayasundar, R. Human brain: biochemical lateralization in normal subjects. Neurol India 2002, 50, 3, 267-271. doi: 10.2463/mrms.2.117

12. Lorenz, M.V.; Marcus, H.S.; Bots, M.L.; Sitzer, M. Prediction of clinical cardiovascular events with carotid intima-media thickness: A systematic review and meta-analysis. Circulation 2007, 115, 459467. doi:10.1161/circulationaha.106.628875

13. Geyer, J.D.; Gomez, C.R. Stroke. A Practical Approach. Lipppicott Williams\&Wilkins, 2009; 336.

14. Fisher, M.; Bogousslavsky, J. Current review of cerebro-vascular diseases. Fisher, M.; Scshebitz, B., Ed. CM: 1996, p 105. doi:10.1007/978-1-4684-0001-4

15. Matthew, M.Y.; Sattar, N.; McMurray, J.J.V.; Packard, C.J. Statins in the prevention and treatment of heart failure: a review of the evidence. Current Atherosclerosis Reports 2019, 21, 41, 1-8. doi: 10.1007/s11883-019-0800-z

16. Kuznetsov, V.V.; Yurchenko, F.V.; Zazagarska, T.V. Simvastin effects on the blood lipid composition and nervous system functioning in elderly patients with cerebral stroke. Blood Circulation and Hemostasis 2009, 1-2, 115-120.

17. Kuznetsov, V.V.; Yurchenko, F.V.; Schulzenko, D.V. Mechanisms of symvastatin effect on functional status of CNS in patients with ischemic stroke. 3rd Inter. Conf. on hypertension, lipids, diabetes and stroke prevention. Abstract Book: Berlin, 2010; p 232.

18. Herder, M.; Johnson, S.G.; Arntsen, K.A. Risk factors of increase of intima-media complex and overall plague area. Stroke 2012, 4, 28, 13-18. doi:10.1161/STROKEAHA.111.646596

19. Suzuki, N.; Sato, M.; Houkin, K.; Terayama, Y.; Uchiyama, S. et al. One-year atherothrombotic vascular events rates in outpatients with recent non-cardioembolic ischemic stroke: The EVEREST (Effective Vascular Event Reduction after Stroke). J Stroke Cerebrovasc Dis 2012, 21, 4, 245-253. doi:10.1016/j.jstrokecerebrovasdis.2012.01.010 
20. Fokin, V.F.; Bogolepov, I.N.; Gutnik, B. Rukovodstvo po funktsional'noy mezhpolusharnoy asimmetrii [Manual on functional interhemispheric asymmetry (in Russian)]. Science World: Moscow, 2009

21. Leeanne, M.C. Stroke Rehabilitation. Oxford University Press 2012. doi:10.1093/med/9780199797882.001.0001

22. Gnezditskii, V.V. Obratnaya zadacha EEG i klinicheskoy entsefalografii [Reverse task of EEG and clinical encephalography (in Russian)]. Medpress-inform: Moscow, 2004; p 624. 